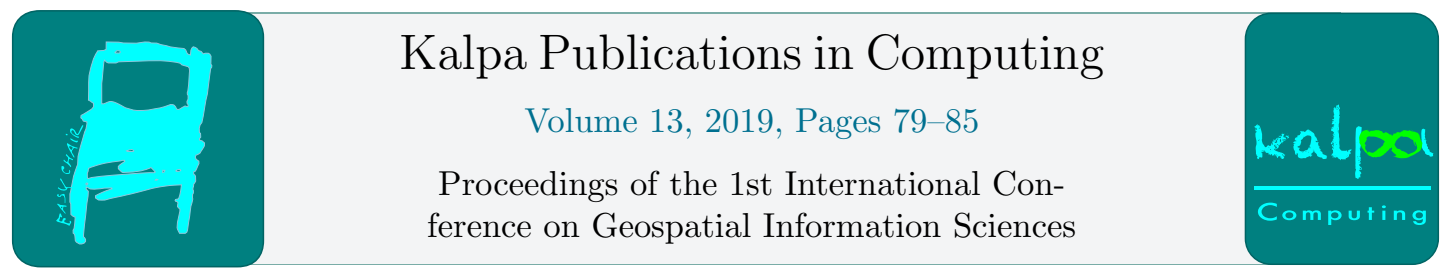

\title{
Possibilities of milpa identification in Yucatan through remote sensing techniques and Sentinel-2 data
}

\author{
Juan C. Valdiviezo-Navarro ${ }^{1}$, Adán Salazar-Garibay ${ }^{1}$, Karla Juliana \\ Rodríguez-Robayo ${ }^{1}$, Lilián Juárez ${ }^{1}$, Maria Elena Méndez-López ${ }^{1}$, and Alejandro \\ Téllez-Quiñones ${ }^{1}$
}

CONACYT - Centro de Investigación en Ciencias de Información Geoespacial, Subsede Yucatán, Yucatán, México. jvaldiviezo@centrogeo.edu.mx

\begin{abstract}
Maya milpa is one of the most important agrifood systems in Mesoamerica, not only because its ancient origin but also due to lead an increase in landscape diversity and to be a relevant source of families food security and food sovereignty. Nowadays, satellite remote sensing data, as the multispectral images of Sentinel-2 platforms, permit us the monitoring of different kinds of structures such as water bodies, urban areas, and particularly agricultural fields. Through its multispectral signatures, mono-crop fields or homogeneous vegetation zones like corn fields, barley fields, or other ones, have been successfully detected by using classification techniques with multispectral images. However, Maya milpa is a complex field which is conformed by different kinds of vegetables species and fragments of natural vegetation that in conjunction cannot be considered as a mono-crop field. In this work, we show some preliminary studies on the availability of monitoring this complex system in a region of interest in Yucatan, through a support vector machine (SVM) approach.
\end{abstract}

\section{Introduction}

The Maya milpa in the Yucatan Peninsula is a polyculture complex system for the production of corn, bean and squash, accompanied by other economic activities, such as family-owned backyard gardens, extraction of products from the surrounding forest, e.g., firewood, wildlife meat, medicinal plants, and honey [12,3]. Hence, the Maya milpa is a highly productive system immersed in a matrix of family gardens, fallow forests in different stages of rest and fragments of natural vegetation. Considering the environmental characteristics of the Yucatan Peninsula, such as shallow and eroded soils, very high temperatures and low rainfall, an important proportion of the Maya milpa crops is shifting agriculture.

The Maya milpa has been the food base for farmers in the Peninsula during the last three centuries [14], providing food security and food sovereignty [10]. Although milpa is part of the people's culture and customs in the region, there are some factors promoting the system loss, e.g., the excessive use of agrochemicals, climate pattern changes, and rural migration. In order to understand the degree of affection of these factors on the milpa system, its spatial

O. S. Siordia, J.L. Silván Cárdenas, A. Molina-Villegas, G. Hernandez, P. Lopez-Ramirez, R. Tapia-McClung, K. González Zuccolotto and M. Chirinos Colunga (eds.), iGISc 2019 (Kalpa Publications in Computing, vol. 13), pp. $79-85$ 
analysis to identify characteristic patterns and its interaction with the surrounding forests become necessary.

The identification of milpa cultivation using remotely sensed data is one of the most relevant challenges due to the following reasons: the diversity of crops inside the milpa system, the average size of milpas ( $<3$ hectares), the characteristic of shifting crops, and the surrounding forest dynamic. In this sense, there are a few researches addressing the study of polyculture with remote sensing data. For example, authors in Ref. [2], examined changes in the spatial characteristics of milpa cultivation in Peto municipality (Yucatan state) from 1988 to 2003. For this purpose, unsupervised classifications were performed from Landsat TM images to identify milpa clearings, grass, and forest. In order to improve milpa clearings classification, a texture analysis was realized based on principal component analysis (PCA) computed from the input images. Several studies such as Bermeo et al. in [1] have estimated the land availability for milpa cultivation in an indigenous and agro-biodiverse area of the center of Mexico (Puebla). The authors combined land use derived from National remote sensing data with information on agrarian census data. They proposed an spatial index to characterize the intensity of traditional agricultural practices, and their strategy was to analyze the difference between the total area and the extensive agricultural systems surface. In addition, Civantos et al. in [6] analyzed the relationship between the richness of passerine species and the functional dynamics of ecosystems in a National Park in Portugal. The variables to measure landscape seasonality were obtained with Landsat-8 images. Weissteiner et al. in [4] designed a farmland heterogeneity indicator based on structural elements of the images such as edge density and texture of patches in order to characterize agricultural landscape, transition zones of land use/land cover and their changes over time and thus the characterization of heterogeneous landscapes. Lyubenova et al. in [11] have monitored a field with two main crops -winter corn and barley- using multispectral and thermal imagery from an Unmanned Aerial Vehicle (UAV). The authors computed three basic vegetation indices in order to identify the growth of crops throughout the time of the analysis. Their work have showed that mutispectral data have great potential in agriculture.

This research presents preliminary results on the identification and further classification of Maya milpa areas in Yucatan, through remote sensing techniques applied to Sentinel-2 satellite

data. In the subsequent sections we describe the materials and methods used, as well as some classification results in two localities of Valladolid, a municipality of Yucatan (Mexico).

\section{Study areas}

Yucatan state, part of the Yucatan peninsula, is characterized by numerous milpa areas; in particular, the municipality of Valladolid at the east of the state, has a significant surface of its territory under communal land tenure, called ejidos, where milpa cultivation is still a common practice; in this research we have restricted our study to two ejidos in Valladolid, named Popola and Kanxoc (Fig. 1).

Popola, located at $20.7332^{\circ}$ latitude and $-88.2371^{\circ}$ longitude (in the northwest part of Valladolid) is an ejido with 4176 inhabitants, $99.3 \%$ of them are indigenous [8]. Soil types include Chromic Luvisol and Rendzina.

On the other hand, Kanxoc is located in the southeast of Valladolid, at a $20.6162^{\circ}$ latitude and $-88.0986^{\circ}$ longitude; from a total population of 3126 inhabitants in the ejido, $99.8 \%$ of them are indigenous [8]. Soil types in the region include Chromic Cambisol and Rendzina. Kanxoc is considered as one of the most traditional regions of Yucatan due to its historical and cultural continuity, representing an important area of milpa cultivation.

The weather in both localities is warm subhumid, with rains in summer, average humidity 


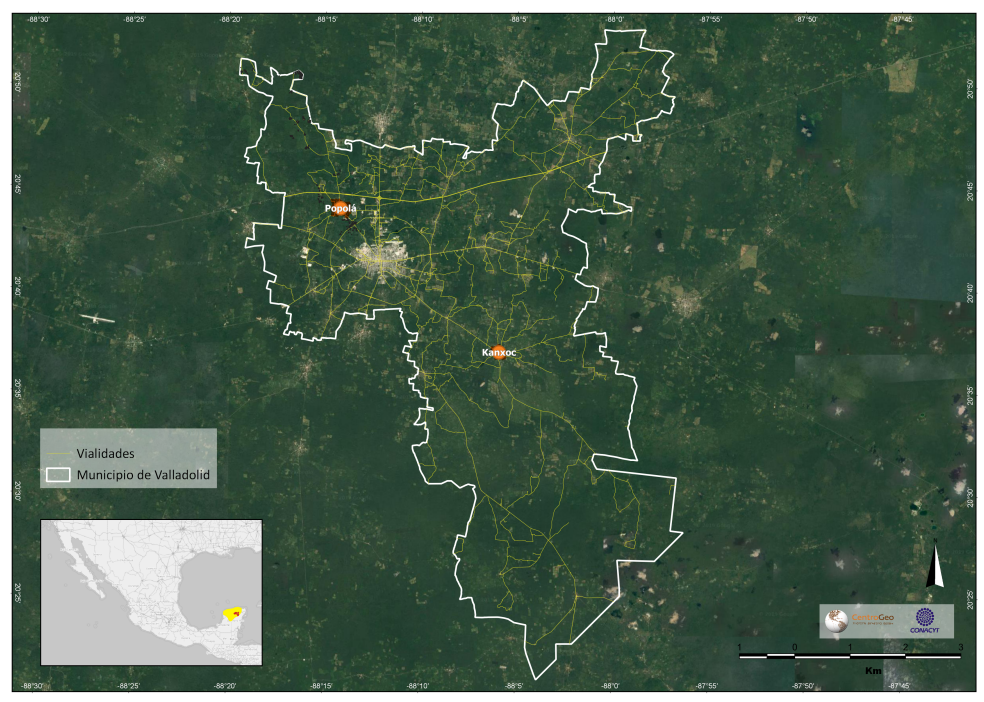

Figure 1: Study areas as part of the municipality of Valladolid.

of $99.6 \%$, average annual temperature of $25.7^{\circ} \mathrm{C}$, and average annual rainfall of $1030 \mathrm{~mm}$ [5]. The map displayed in Fig. 1 shows the location of both localities.

\section{Materials and methods}

\subsection{Data collection}

The fieldwork and data collection realized to determine specific characteristics of milpa areas involved three steps; the first one was the design of a structured survey to gather information about milpa plots. The survey covers three different sections with questions regarding: a) General information about the milpa plot (owner, location, surface area, cultivated species), b) Description and dates of important farm activities (slash, burn, sowing, harvest), c) Characteristics of the surrounding forest (age, frequent species, uses, surface area).

The second step was the selection of the milpa farmers. In each locality we sought for farmers with milpa plots during the year 2018, who agreed to answer the survey and the georeferenciation of their milpa plots. Finally, the third step involved the use of a global positioning system (GPS) to georeferenciate milpa plots around their perimeters. Thus, 12 polygons and surveys were conducted: 6 in Popolá and 6 in Kanxoc. This information was gathered between November 2018 and July 2019.

\subsection{Image sets}

Our experiments were realized based on Sentinel-2 satellite images registered in different months along 2018, including January, April, and October. Each image collection is conformed by 13 spectral bands covering the spectral interval from 443 to $2190 \mathrm{~nm}$, at different spatial resolutions ranging from 10 to $60 \mathrm{~m}$.

In order to observe and identify milpa patterns, the image sets were pre-processed following this process; First, radiometric calibration and atmospheric correction were performed to derive 
land surface reflectance. Second, since spectral bands have different spatial resolutions, all image sets were re-sampled to the finest available resolution. Then, an image subset covering the two study areas was defined for all cases. Finally, various band combinations were produced and displayed as false color images in order to highlight milpa cultivations.

\subsection{Classification process}

It is important to consider that notwithstanding the modern approaches of the artificial intelligence and deep learning [15] tend to automation or null supervision, the classification of documents, images or other objects, at some point in the genesis of the algorithms it requires human training. In this sense, supervised classification methods are the most natural and simple techniques to separate data sets by a simple training process. This is the case of the so called support vector machine (SVM), the non-linear version or the generalization of a linear hyper-plane model that represents a maximal margin classifier [9]; SVM has demonstrated to be a robust enough technique with moderate cost and good accuracy in different remote sensing applications. For the generalization of the maximal margin classifier, the modern SVM algorithms employ different base functions known as kernels. In the current application related to milpa areas classification, radial base functions were used as kernels for the classification process.

\section{Preliminary results}

\subsection{Milpa system characterization in Popola and Kanxoc}

The 12 milpas considered in the study had an average area of 1,2 hectares and supplied an average of 6 products (2-11 products). The main products harvested in the plot were: maize, beans, squash, chile, camote (sweet potato), macal (local tuber), jicama, watermelon and cantaloupe.

The activities developed in the milpa plot are mainly four: slash, burn, sowing and harvest. The slash activity was done since November to May, the burn practice was mainly in April or May, the sowing of seeds was done in the period May-June, and the harvesting is practiced since October to January.

The entire milpa plots were surrounding by forest coverage in different successional state (forest age). The youngest forests were 10 years old, and the oldest 70 years old. The average age of the surrounding forest was 28 years old.

\subsection{Classification results}

The collected milpa polygons were projected onto the multispectral collections in order to identify milpa patterns. Since the working spatial resolution of the imagery was $10 \mathrm{~m}$, spectral mixtures of the different species present in the crops were observed in the produced false color images. Based on our experiments we found that combination of bands in the spectral portions covering the short-wavelength infrared (SWIR), infrared (IR), and green (G), respectively, allowed to visually identify milpa plots in the study areas. Figure 2 shows a false color image, produced by combination of bands in the aforementioned portions, for images registered in April and October, respectively. Notice that a milpa plot is enclosed by a red polygon.

As depicted in Fig. 2 and supported by the surveys, milpa plots can be distinguishable in months were most crops are ready to be harvested. Hence, a supervised classification process via SVM was performed based on the October image. For this purpose, the spectral pixels enclosed 


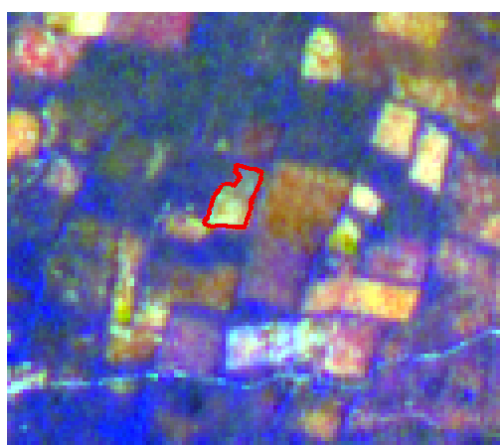

(a)

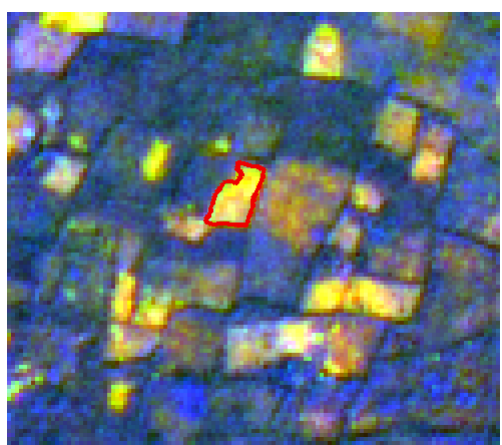

(b)

Figure 2: False color images of a portion of Kanxoc, produced by combination of bands 11, 8 , 2, registered in (a) April and (b) October, respectively. The red polygon denotes a milpa plot

by 9 milpa polygons were used as seed points for the training step; the remaining three polygons were used for validation purposes. Figure 3 displays the classification result where milpa areas (represented in yellow polygons) were identified according to the aforementioned process.

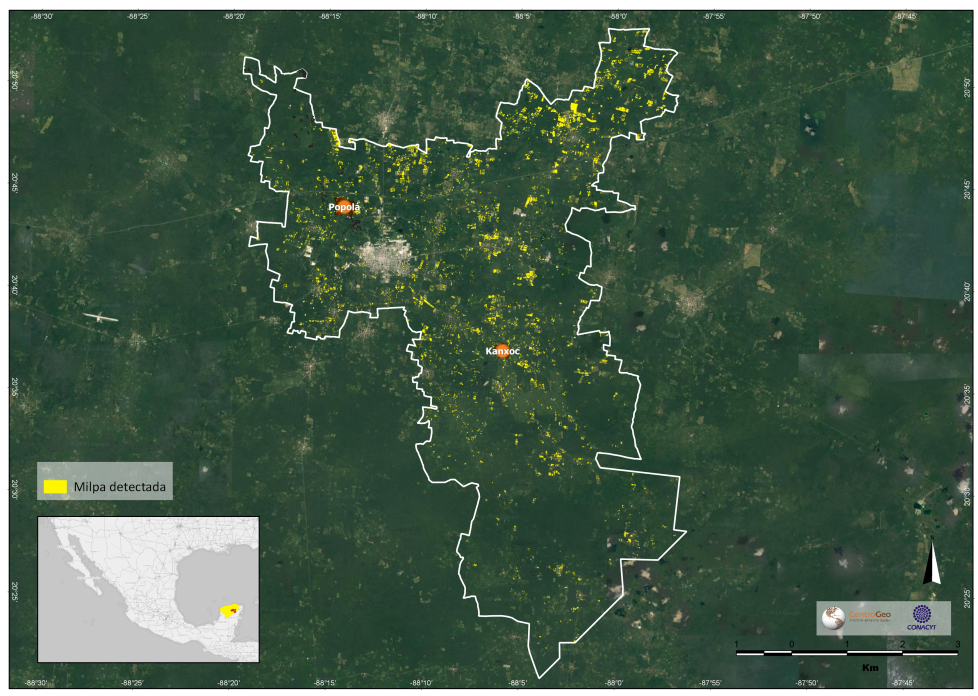

Figure 3: Classification of milpa areas based on SVM.

As we previously mentioned, pixels belonging to three polygons were used as reference to assess the classification process. Table 1 presents the commission and omission errors, the overall accuracy and the Kappa coefficient for classes labeled as Milpa and Background. Although the assessment seems to be good enough, the validation process should be strengthened by acquiring more polygons and a higher resolution image of the study areas. Nevertheless, our preliminary results state that the hidden polygons were satisfactory identified with the proposed technique, which states that Maya milpa plots are suitable to be identified using remote sensing data. 
Table 1: Accuracy assessment of the proposed methodology for milpa identification

\begin{tabular}{|c|c|c|c|c|}
\hline Class & Commission (\%) & Omission (\%) & Overall acc. (\%) & Kappa \\
\hline Milpa & 0 & 22.27 & 96 & 0.86 \\
Background & 2.23 & 0 & & \\
\hline
\end{tabular}

\section{Discussion and conclusion}

Milpa in the Yucatan region is an heterogeneous and complex system that is reflected in socioeconomic, environmental and landscape features. It involves indigenous people with traditional knowledge around the use and preservation of forests, and a matrix of polycultures in a small land area. Due to its complexity, new and modern techniques in data science should be proposed. Its monitoring through multispectral images demands on an appropriate validation stage, and, although the SVM technique seems to be working in our preliminary results, an exhaustive accuracy analysis, by considering several georeferenced polygons, should be conducted.

The spatialization of the Maya milpa with remote sensing tools is relevant for decision makers to measure the degree of threat that this system currently has, and the implications that this entails in matters of food security and sovereignty and conservation of agrodiversity. This approach to identifying the Maya milpa in the complex landscape matrix of the Yucatan Peninsula can save many resources for long-term monitoring of the system.

There is not precise information about the quantity and location of Maya milpa, but there are two agricultural reports to compare the surface area in milpa detected in Valladolid by the SVM technique (3236 hectares). The last national agricultural census developed in 2007 estimated in Valladolid 5112 hectares under maize crop [7]. On the other hand, the Agrifood and Fisheries Information Service reported 7101 hectares under corn crop in Valladolid in 2018 [13]. According to national data it is possible that the SVM technique is underestimating the milpa area. Finally, additional and complementary studies with other more robust techniques, as deep-learning, neural networks, or data-fusion with polarimetric radar sensors, should be also considered.

\section{Acknowledgments}

Authors want to thank to Nicolás Chan for the support through collecting field data used in our experiments.

\section{References}

[1] M. Galeana A. Bermeo, S. Couturier. Conservation of traditional smallholder cultivation systems in indigenous territories: Mapping land availability for milpa cultivation in the huasteca poblana, mexico. Applied Geography, 53:299-310, 2014.

[2] J. Southworth A. E. Daniels, K. Painter. Milpa imprint on the tropical dry forest landscape in yucatan, mexico: remote sensing and field measurement of edge vegetation. Agriculture, Ecosystems and Environment, 123(4):293-304, 2008.

[3] K. Emery A. Ford. Exploring the legacy of the maya forest. Journal of Ethnobiology, 28(2):147-153, 2008. 
[4] Maria Luisa Paracchini Christof J. Weissteiner, Celia García-Feced. A new view on eu agricultural landscapes: Quantifying patchiness to assess farmland heterogeneity. Ecological Indicators, 61(2):317-327.

[5] CONAGUA. Precipitación pluvial anual, 2015.

[6] J. Goncalves B. Marcos P. Alves-J.P. Honrado E. Civantos, A.T. Monteiro. Patterns of landscape seasonality influence passerine diversity: Implications for conservation management under global change. Ecological Complexity, 36:117-125, 2018.

[7] INEGI. Censo agrícola, ganadero y forestal 2007, 2007.

[8] INEGI. Censo de población y vivienda 2010, 2010.

[9] T. Hastie J. Gareth, D. Witten and R. Tibsshirani. An introduction to statistical learning with applications in R. Springer, NY, 2013.

[10] A. Aguilar-Jiménez M. Ricalde-Pérez L. Salazar-Barrientos, M. Magaña-Magaña. Factores socioeconómicos asociados al aprovechamiento de la agrobiodiversidad de la milpa en yucatán. Ecosistemas y recursos agropecuarios, 3(9):391-400, 2016.

[11] Paulina Lyubenova Raeva, Jaroslav Šdina, and Adam Dlesk. Monitoring of crop fields using multispectral and thermal imagery from uav. European Journal of Remote Sensing, 52(sup1):192201, 2019.

[12] C. Rasmussen S. Terán. La milpa de los mayas: La agricultura de los Mayas prehispánicos y actuales en el noreste de Yucatán. Universidad Autónoma de Yucatán, Mexico, 1994.

[13] SADER. Estadística de producción agrícola, 2018.

[14] N. Vavilov. Origin and geography of cultivated plants. Cambridge University Press, United Kingdom, 2009.

[15] Z. Wang W. Rawat. Deep convolutional neural networks for image classification: a comprehensive review. Neural Computation, 29(9):2352-2449, 2017. 